\title{
Teratoma of the anterior mediastinum presenting as a cystic neck mass: a case report
}

\author{
Gaurav Agarwal*1 and Dilip K Kar ${ }^{2}$
}

Address: ${ }^{1}$ Department of Endocrine Surgery, Sanjay Gandhi Postgraduate Institute of Medical Sciences, Raebareli Road, Lucknow- 226014, India and ${ }^{2}$ Dept of Surgical Oncology, JLN Cancer Hospital, Bhopal, India

Email: Gaurav Agarwal* - gaurav@sgpgi.ac.in; Dilip K Kar - dilipkars@yahoo.com

* Corresponding author

Published: 28 January 2008

Journal of Medical Case Reports 2008, 2:23 doi:10.1186/1752-1947-2-23

This article is available from: http://www.jmedicalcasereports.com/content/2/I/23

(c) 2008 Agarwal and Kar; licensee BioMed Central Ltd.

This is an Open Access article distributed under the terms of the Creative Commons Attribution License (http://creativecommons.org/licenses/by/2.0), which permits unrestricted use, distribution, and reproduction in any medium, provided the original work is properly cited.
Received: 22 February 2007

Accepted: 28 January 2008

\begin{abstract}
Introduction: Teratomas of anterior mediastinum are rare tumors and are often slow growing, asymptomatic and detected incidentally on chest imaging. Results of surgical resection are very satisfactory.
\end{abstract}

Case presentation: A 19-years old male presented with an asymptomatic cystic neck mass. $X$ ray and $C T$ scan of chest and neck showed an extrathyroidal multi-septate, predominantly cystic neck mass, that was continuous with a solid intrathoracic mass extending up to the level of right atrium and which contained areas of calcification and cystic necrosis. The mediastinal structures did not show any features of compression or infiltration. Fine needle aspiration cytology from the neck mass was suggestive of a dermoid cyst. In view of the extent and uncertain pathological nature of the tumor, it was excised via a combined cervical and trans-sternal route. Histo-pathology of the resected specimen confirmed the diagnosis of a mature cystic teratoma. The patient made an uneventful recovery, and after five years of follow-up, he has been symptom free with no clinical or radiological evidence of recurrent disease. We discuss the role of imaging and the need for surgical treatment to avoid possible catastrophic complications in patients with cervical and mediastinal masses of uncertain histological nature.

Conclusion: A mediastinal teratoma may rarely present as a cystic neck swelling due to its cephalad extension. This entity needs to be considered in cases where clinical and investigative work-up fail to provide a convincing clue to a primary neck pathology as cause of a cystic neck swelling.

\section{Introduction}

Teratomas of the anterior mediastinum account for 8$13 \%$ of tumors in this region [1]. The majority of these teratomas are located in the anterior mediastinum with only $3-8 \%$ arising from the posterior mediastinum [2-4]. These slow growing tumors are often asymptomatic and are often detected incidentally on chest radiographs. Complications such as atelectasis, adhesion to, or com- pression of, adjacent structures, or malignant transformation are occasionally encountered. Results of surgical resection are usually very satisfactory.

We report the case of a young adult male who presented with a cystic neck mass, due to degeneration of a cervical extension of a mature teratoma of the anterior mediasti- 

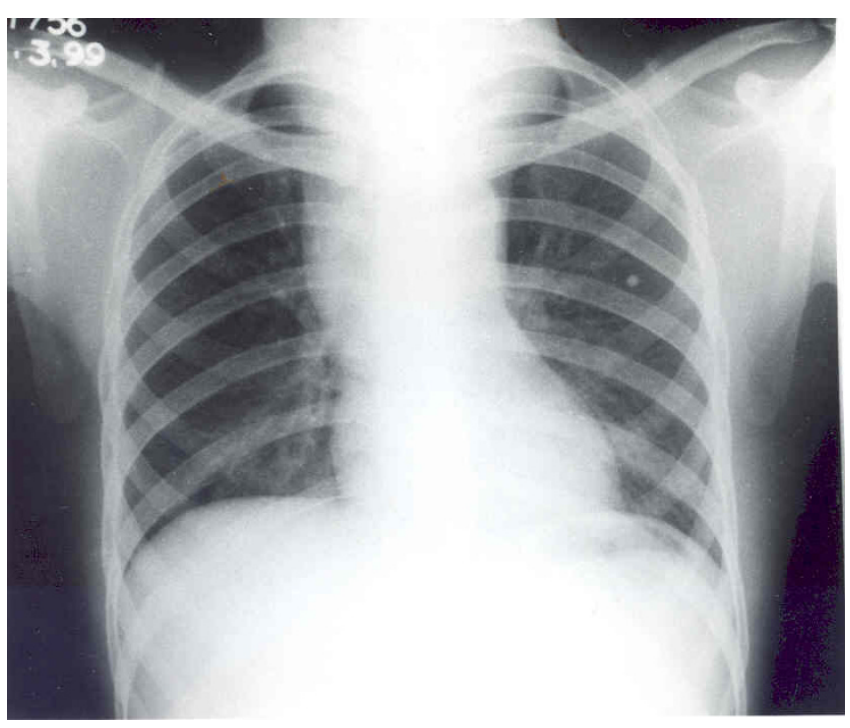

Figure I

Chest $\mathrm{X}$-ray ( $\mathrm{P}-\mathrm{A}$ view) showing widening of the mediastinum and a soft tissue swelling in the neck, continuous with the mediastinal shadow.

num. This is an unusual presentation of an uncommon pathology.

\section{Case presentation}

A 19 years old male presented with a rapidly progressing painless neck swelling of 3 months duration. There were no complaints of fever or weight loss or symptoms suggestive of compression of adjacent structures. The patient was afebrile and had a cystic, non-tender, non-translucent and smooth swelling occupying the whole of the neck anteriorly, extending from the hyoid bone to the suprasternal notch. The lower limit of the swelling could not be reached. There were no neck nodes or dilated tortuous neck or chest wall veins.

Chest X-ray revealed widening of the mediastinum and a soft tissue neck swelling, continuous with the mediastinal shadow (Fig 1). On neck ultrasonography, a predominantly cystic, multiseptate mass lying superficial to the thyroid lobes was evident. Fine needle aspirate cytology from the swelling showed largely necrotic material with few macrophages and mixed inflammatory cells on a background of proteinacious material, suggesting a diagnosis of a dermoid cyst. There were no acid-fast bacilli, bacterial and fungal elements on microscopy and culture. 99mTc-thyroid scan ruled out a thyroid lesion. Contrast enhanced CT of neck and mediastinum (Fig 2 and 3) showed a multi-septate, predominantly cystic neck mass, superficial to thyroid and strap muscles. The mass was continuous with a more solid intrathoracic mass with areas of calcification and cystic necrosis, extending up to the level of right atrium. The trachea was shifted to the right but there was no compression or infiltration of great vessels or mediastinal structures. There were no mediastinal lymph nodes and pulmonary lesions. A diagnosis of anterior mediastinal teratoma with cervical extension was made.

The patient was operated upon through a neck crease and median sternotomy incision under general anesthesia with endotracheal intubation. The posterior wall of the mass in the neck was adherent to the strap muscles. A solid mediastinal tumour with areas of necrosis, which seemed to be arising from the thymus gland, was found on sternotomy. The tumor derived its blood supply from the thoracic vascular channels as direct branches from aortic arch and the subclavian artery. There were no vessels feeding or draining the tumor in the neck. The mass was adherent to but did not infiltrate, the innominate vein. The neck and thoracic mass, along with a densely adherent $4 \times 3 \mathrm{~cm}$ area of left mediastinal pleura, were removed in continuity, preserving nearby vital structures.

The resected surgical specimen was subjected to a detailed histopathological evaluation. On naked eye examination, the globular brownish mass measured $16 \times 7 \times 2 \mathrm{cms}$. The cut surface of the mass was cystic, filled with yellow pultaceous material and a mass of hair. There was a solid area projecting into the lumen of the cystic area, which had multiple cysts filled with gelatinous material. On microscopy, the cyst wall showed predominantly degenerate necrotic area, associated with inflammatory cells. Sections from the solid areas revealed cartilage, osseous tissue and nerve bundles with ganglionic cells, respiratory epithelium and sero-mucinous glands embedded in dense fibrocollagenous and fibro-muscular tissue. The lesion was thus labeled as a mature cystic teratoma on basis of the histopathological features.

The patient made an uneventful postoperative recovery. After five years in the follow-up, the patient has remained asymptomatic, and follow-up imaging studies in the form of chest x-ray examination undertaken 3, 14 and 36 months after operation, as well as a contrast enhanced CT scan of the neck and mediastinum performed 14 months after operation, have not shown any residual or recurrent mass.

\section{Discussion}

Teratomas are congenital tumors that contain derivatives of all three germ layers and arise from pluripotent embryonal cells. They commonly occur in ovaries, testes, retroperitoneum and the sacro-coccygeal region. Superior mediastinal teratomas are usually asymptomatic till late, and are often discovered incidentally on chest $\mathrm{x}$-ray. Symptoms such as chest pain, dyspnoea or cough are a 


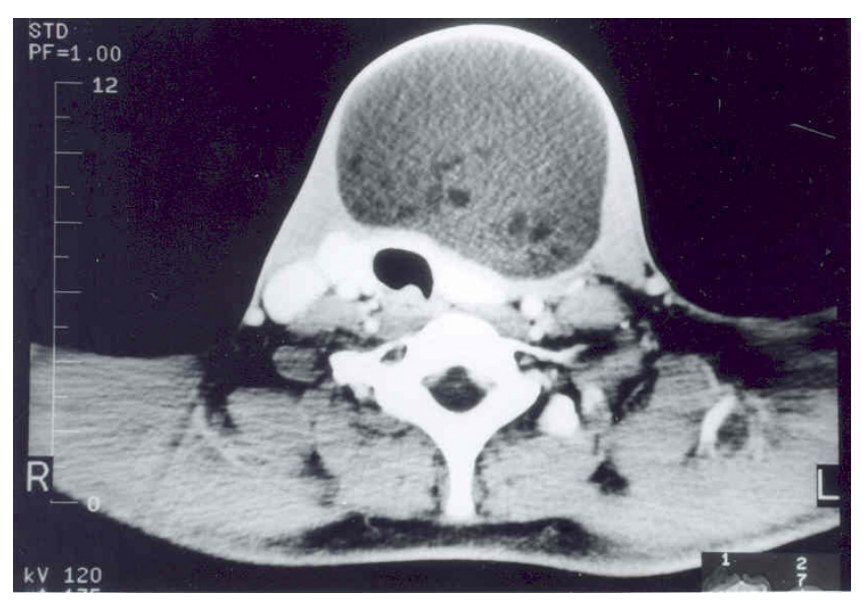

\section{Figure 2}

Contrast-enhanced CT scan of the neck showing a multi-septate cystic neck mass, lying superficial to the thyroid lobes and strap muscles.

result of compression of nearby structures. Rarely, the teratoma may rupture into tracheo-bronchial tree or result in SVC syndrome or pneumonia [5]. The interesting feature of our patient was that he presented with a rapidly enlarging, yet other wise asymptomatic, neck mass. Perhaps it was because the mediastinal mass found an escape route into the neck, tha our patient did not have features of mediastinal compression, despite the large tumor size.

Chest X-ray is an important aid in diagnosis of a mediastinal teratoma. Mediastinal CT scan demonstrates the extent of a mass better than conventional radiography. It can also detect fatty or cystic areas in mediastinal masses, but this information will not obviate the need for surgical resection to establish the final diagnosis [4]. CT scan is helpful in defining invasion of adjacent structures and thus assists planning surgical intervention [5]. CT scan (Fig 2 and 3) of neck and mediastinum in our patient established the continuity of mediastinal mass into the neck and detected adherence of the mass to pericardium.

Complete curative surgical removal of a mediastinal teratoma is the treatment of choice, as it establishes the diagnosis, besides preventing life threatening complications in many patients [6]. Malignant mediastinal teratomas account for roughly $1-5 \%$ of all mediastinal tumors $[7,8]$. Invasion or great vessels, myocardium, lung and phrenic nerves should be taken as indicators of malignancy, and may necessitate extensive operation in selected patients [7]. Complications of extensive surgical procedures such as pneumonectomy, rather than the disease itself, may prove fatal [4]. Adherent mediastinal pleura and pericardium can be dealt with by removal of the involved portions. As most mediastinal teratomas are benign, even a

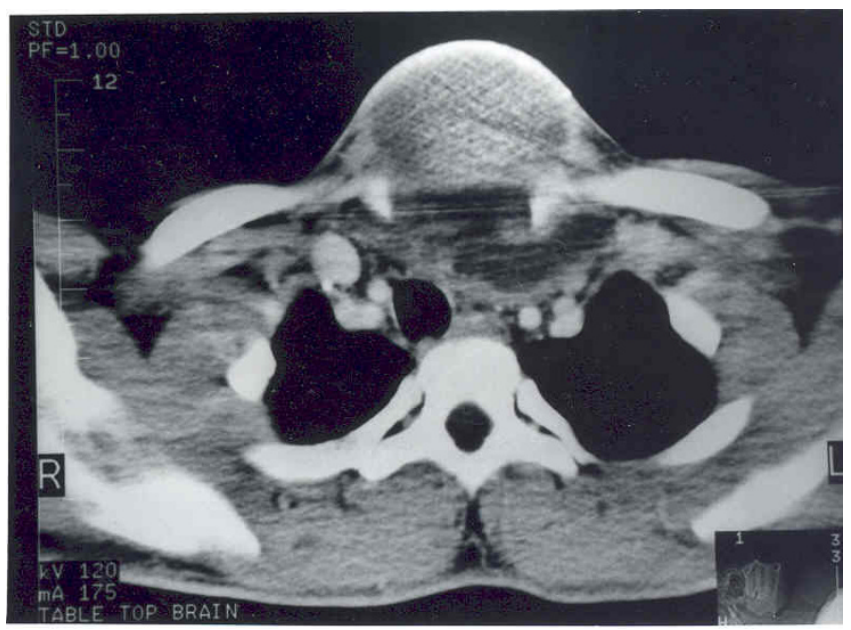

Figure 3

Contrast-enhanced CT scan of the upper thorax showing extension of a complex cystic mass and displacement of the trachea with compression of major vessels.

subtotal resection conserving adherent vital structures provides excellent results. In present era of modern surgical practices, excellent outcome has been the rule [5].

Our patient represents an unusual presentation of this not so uncommon pathological entity. Extension of a mediastinal teratoma into the neck and its cystic degeneration gave rise to this presentation. A search of the English language medical literature failed to find many similar cases.

\section{Conclusion}

A cystic neck swelling may rarely be caused by cephalad extension of a mediastinal teratoma. This entity needs to be considered in cases where clinical and investigative work-up fail to provide a convincing clue to a primary neck pathology as cause of a cystic neck swelling.

\section{Abbreviations}

CT: Computed tomography

FNAC: Fine needle aspiration cytology

\section{Competing interests}

The author(s) declare that they have no competing interests.

\section{Authors' contributions}

GA conceived the case report, contributed to collection of clinical details and writing, reviewing and finalization of the manuscript; DKK prepared the first draft besides contribution to collection of clinical details and illustrations. Both authors reviewed and finally approved the final manuscript. 
Written informed consent was obtained from the patient for publication of this case report and accompanying images. A copy of the written consent is available for review by the Editor-in-Chief of this journal.

\section{References}

I. Wychulis AR, Payne WS, Clagett OT, Woolner LB: Surgical treatment of mediastinal tumors. J Thorac Cardiovasc Surg 197I, 62:379-391.

2. Philip WP, Harrison K, Cruickshank DB: A posterior mediastinal dermoid tumor with marked anatomical differentiation. Tho$\operatorname{rax}$ 1954, 9:245-247.

3. Weinberg B, Rose JS, Efremidis SC, Kirschner PA, Gribetz D: Posterior mediastinal teratoma (cystic dermoid) diagnosis by computerized tomography. Chest 1980, 77:694-695.

4. Lewis BD, Hurt RD, Payne WS, Farrow GM, Knapp RH, Muhm JR: Benign teratomas of the anterior mediastinum. J Thorac Cardiovasc Surg 1983, 86(5):727-73I.

5. Nichols CR: Mediastinal germ cell tumors. Chest 199I, 99:472-79.

6. Verhaeghe W, Meysman M, Noppen M, Monsieur I, Lamote J, Op De Beeck B, Pierre E, Vincken W: Benign cystic teratoma: an uncommon cause of anterior mediastinal mass. Acta Clin Belg 1995, 50(2): 126-9.

7. Levitt RG, Husband JE, Glazer HS: CT of Primary Germ-Cell Tumors of the Mediastinum. Am J Radiol I984, I 42:73-78.

8. Ousehal A, Skalli A, Nejjar M, Belaabidia B, Kadiri R: Malignant bilateral mediastinal teratoma: a case report. J Radiol 200I, 82(2): 174-6.

Publish with Biomed Central and every scientist can read your work free of charge

"BioMed Central will be the most significant development for disseminating the results of biomedical research in our lifetime. "

Sir Paul Nurse, Cancer Research UK

Your research papers will be:

- available free of charge to the entire biomedical community

- peer reviewed and published immediately upon acceptance

- cited in PubMed and archived on PubMed Central

- yours - you keep the copyright

Submit your manuscript here:

http://www.biomedcentral.com/info/publishing_adv.asp 